\title{
Social Media in the Times of the Crisis of Kosovo
}

\author{
Njomza Krasniqi \\ European University of Tirana, Department of Political Science, Profile-Communication \\ krasniqi.njomza@gmail.com
}

\section{Doi:10.5901/mjss.2015.v6n2s5p206}

\begin{abstract}
With the development of the technology also has come the development of media, and especially the social media. One of the most prominent events of the impact of media is the War of Kosovo, and the way it was reflected in the media and the social media. In this paper I will try to paint a clear picture of the development of the events represented both in the historical and media, and the impact that the second had on the first. Its common knowledge nowadays the history of Kosovo and the different crises that it went thru but what it's not very well known is the impact that made the international media and the social one in the way the crises was perceived and what happened for real. It has too little information about the way that the social media impacted the war; the way that it helped in the humanitarian aspect and general modification of the public opinion in sustaining and protecting the innocents. And this is what this paper is about. It's a short research which deals more information on the way the events developed and how the media helped in that development and inferred in protecting and helping the true innocents of the war of Kosovo. How by social networks and internet news people gathered together with no regard of language, nationality or other diversities and helped protect the innocents which were trying to flee the war and protect their families.
\end{abstract}

Keywords: media, social media, crises, war of Kosovo.

\section{Introduction}

Social Media: forms of electronic communication (as Web sites for social networking and micro blogging) through which users create online communities to share information, ideas, personal messages, and other content (as videos) ${ }^{1}$

This is the pragmatic definition what the term Social Media defines. However if we are to analyze it in a more indepth analyzes it's much more than just this. Actually the terminology of Aristotle in describing humans as "social animals", takes a whole new meaning when confronted with the development of technology nowadays. It refer not only to our predisposition to forge bonds which hold on for all our life in most cases, but to the main reason that we consciously make effort, invest energy and a part of ourselves to forge those bonds. And due to the development of technology nowadays the way these bonds are forged is much more different than the way they would have worked in the early 70 es.

Due to this nature of ours, we are bound to use any resources availed to reach these bonds. With the development of technology, what was once perceived as an interpersonal relation developed to a more large scale into what we now call social media. Even though the terminology "social media" was used for the first time in 2004, its beginning is much earlier. The first forms of networking start 1969 with CompuServe which was one of the first major commercial Internet providers in the US. ${ }^{2}$ They used dial-up technology to connect to the web. It was the main provider during the 80-es and part of the 90-es until others companies started to enter the market also. Actually, the first e-mail was sent in 1971 and even though that form of communication is being overrun, it was the prevailing way to communicate remotely for many years.

In 1985, America Online (AOL) was founded and it became one of the most popular early providers of Internet connections. A very popular social media medium is blogging which was started in 1997 and in the same year AOL Instant Message made its debut, allowing people to chat online ${ }^{3}$.

I am listing this history of social media to highlight the fact that the social media did exist since the early 70-es, even though it had still to develop in the way it is now, with Facebook and Twitter, it still played a role in many aspect of

\footnotetext{
1 Webster Dictionary 2012, pg. 135

2 Van Dijck, Jose The Culture of Connectivity: A Critical History of Social Media, January 30, 2013, pg 34.

${ }^{3}$ http://www.inquisitr.com/830664/the-history-of-social-media-when-did-it-really-begin-you-may-be-surprised-infographic/ 
the actual time. Through crude and not overly developed the actual chat rooms and the instant texting of the time played a very big role in the way many crises were managed, especially the crises of Kosovo.

\subsection{The purpose and objectives of the study}

The object of this study is to demostrate the role that the primery forms of the social media, such as chatrooms, blogs and communities on the web played during the Kosovo crise, in not only serving as main points of information, especially for the youth of population but also in provideing help and donations to the refuges hosted in Albania and Machedonia.

\subsection{Research question, hypothesis and methodology of the study}

This work is a description of the situation that developed in Albania and Machedonia in 1999-2000, during the Kosovo war and the way most of the donations and information were provided by the social media more then the other legal authorities such as media or the Public media. The different data was collected thru different sources, mainly statistical ones which are detailed in more depth in part fifth.

Our working hypothesis is: Did the social media played a role in the Kosovo Crises?

\subsection{The importance of this research}

Even though has been many studies for the role the media played in the war of Kosovo, there is next to none regarding the role the social media played, and it also hold significance in my doctoral thesies , "The media impact in Kosovo's Sovrainty. The data obtained from the field and different roare processed under the program SPSS Advanced Statistics

\subsection{Social media in Albania and Macedonia}

The two main countries that assisted the population escaping the war of Kosovo during 1999 were Albania and Macedonia, where the main part of the migrating population found refuge. Of course there were many more countries that helped with donations and asylum for the escaping refugees, but the main points of recollections were the above mentioned countries. Now even thought the general technological development in these countries were not par to the rest of the world they still had a significant investment in technology and mainly in the computer and internet industry. ${ }^{4}$ The more popular ones were the internet-cafes, which reached a percentage of $34 \%$ in Albania, area coverage and $58 \%$ in Macedonia, area coverage. It is also interesting to mention that the main target of these internet cafes was teenagers and youth whom used them mainly to connect to the outside world across the border of their countries.

This is a general picture to illustrate that even though isolated and not very free to move at the time, the youth of these two countries were actually practicing a basic form of social media at the primary form in the earliest at the time of Kosovo war. ${ }^{5}$ The main way of communication was the blogs or specific chat rooms in Yahoo or Hotmail and even AOL, though the later was not as popular as the first two. In a way, considering Albanians mostly, these blogs and chat rooms were the main way to exchange information between citizens inside these countries and the ones that were living abroad. It had discussion starting from the basic personal questions of "what do you do for living" to the most hot political issues, regardless of the country that they were developing ${ }^{6}$.

This is the main picture of the actual technological development in these countries at the time. I put these here to actually demonstrate the connections of these two isolated countries to the rest of the world, regardless the fact that both were very fragile countries at the time, coming out of a very deep isolation, Albania more so then Macedonia. Also it is to demonstrate the fact that even though at a first glance these two had no strong connections to circulate information as it was used to at the time, they still had a very strong connection to the external world due to the internet chat rooms and the blogging, and also they were investing in maintaining whole WebPages in the format of communities.

So even though the social media of the time was nowhere as we know it today, and even though the technological

\footnotetext{
${ }^{4}$ Moody, M. (2010). Teaching Twitter and Beyond: Tip for Incorporating Social Media in Traditional Courses. Journal of Magazine \& New Media Research 11(2): pp. 1-9.

${ }^{5} \mathrm{G}$. Salaway, J. Caruso, and R. Mark, 2008. The ECAR study of undergraduate students and information technology, 2008. Boulder, Colo.: EDUCAUSE Center for Applied Research, at http://www.educause.edu/ecar, accessed 15 November 2011.

${ }^{6} \mathrm{~J}$. Schroeder and T.J. Greenbowe, 2009. "The chemistry of Facebook: Using social networking to create an online community for the organic chemistry laboratory," Innovate, volume 5, number 4, 
development was still in the early phases of evolving in these countries, they still practiced the basic form of social media, even though it was mainly to overcome their isolation to the rest of the world, they still made the most of it.

It is of particular interest to mention that the other forms of the electrical media were at the beginning at the time and they didn't offer that much information as the actual ones doo, so that the internet and the chat-rooms or communities were considered as one of the main sources of information.

\subsection{Social media and the Crises of Kosovo}

The role that the media played during the war of Kosovo is a much heated debate then most of the actual issues in the world; however this is not part of this research. The main point of the paper is the role the social media played in providing facts and help in the aiding of the refuges of Kosovo war. The data below was collected using different resources such as statistic publications of Albania and Macedonia Institute of statistics, and also international publications of statistics such as Gallup and Institute of Media in Albania. Also in 2004 a poll was conducted by the graduated students of the Department of Journalism in Tirana, in Albania's and Macedonia's three high schools whom are integrated in the below data.

It was a way for the at the time graduating students to measure the impact of the electronic media in the perception and the role that the blogs and the chat rooms played in the gathering of information and the forming of opinions. The main hot topic at the time, due to the situation in the Balkans, was Kosovo and the war that had ended only four years ago, but since the situation was still unresolved it has still a hot topic ${ }^{7}$.

The poll interviewed the students which were at their last year in 2004, but whom actually were at the first year of high school when the war finished. They were posed a total of four main questions which are posted in the below section. The interest of the time was how much the internet and chat - rooms were used as a primary mean of information. However what came out is better represented in the below data. Also to maintain transparence the students participating on the poll were all of Albania nationality. The schools involved in the polling was Sami Frashri, Cajupi and Qemal Stafa in Tirana, Albania, graduating class of 2004 and "Josip Broz - Tito", Orce Nikolov, College of Europe, in Skopje, Macedonia. Total of participants in the poll were around 700 students.

\subsection{Analyses, Data Interpretation}

According to the information we have received from the students it shows that $19 \%$ of them new about the war due to public media, while $11 \%$ of the students knew because they had a family member in Kosovo, as $5 \%$ of them claimed that knew because of other friends, while according to data shows that $65 \%$ of the students declared that they were using specific communities and chat rooms to get the information in the Kosovo crises. The data shows the main source of information at that time was what we should consider as the social media at the time. It is interesting to note that the one that claimed the chat rooms and communities as the main source of information also gave specific names of them and that they were members as early as 1998 in them in some cases, especially in the Macedonian high schools.

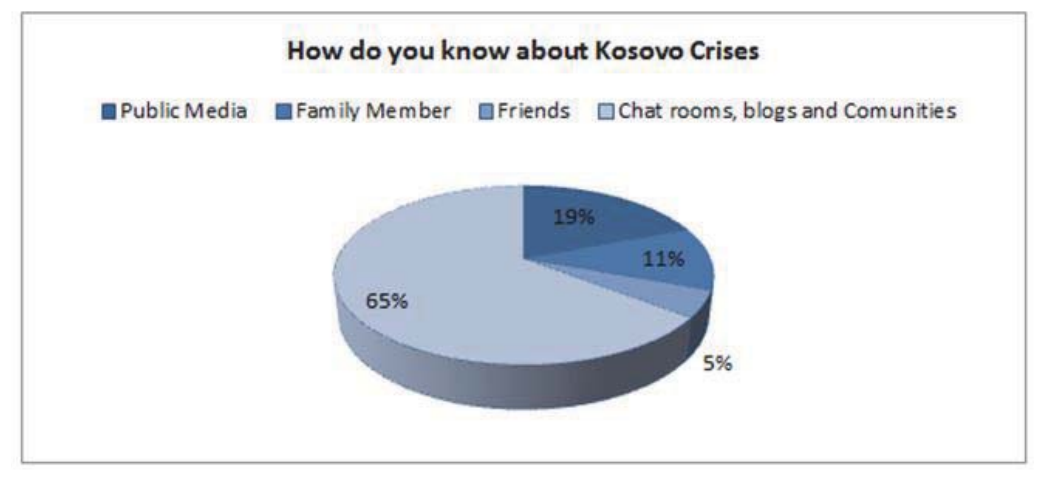

On the question relating to if they knew about ways to give donations to help the refuges of the war and to rebuild the war ruined country and how there were these responses, $36 \%$ of adolescents indicate that they had learned it in the chat rooms, $31 \%$ receive the message due to advertising in the public media, while $25 \%$ of teenagers claimed that they knew

${ }^{7}$ Kist,W. (2012). Class get ready to tweet: Social media in the classroom. Our children. Pg56 
because their family or a friend had done a donation. Only $8 \%$ of adolescents indicate that they didn't know because they were not interested. By this data we can deduce that the main point of information regarding the situation and humanitarian aid was gather thru media and the main one thru social media. ${ }^{8}$ Only a few of them claimed that they didn't know and they came mainly from social welfare.

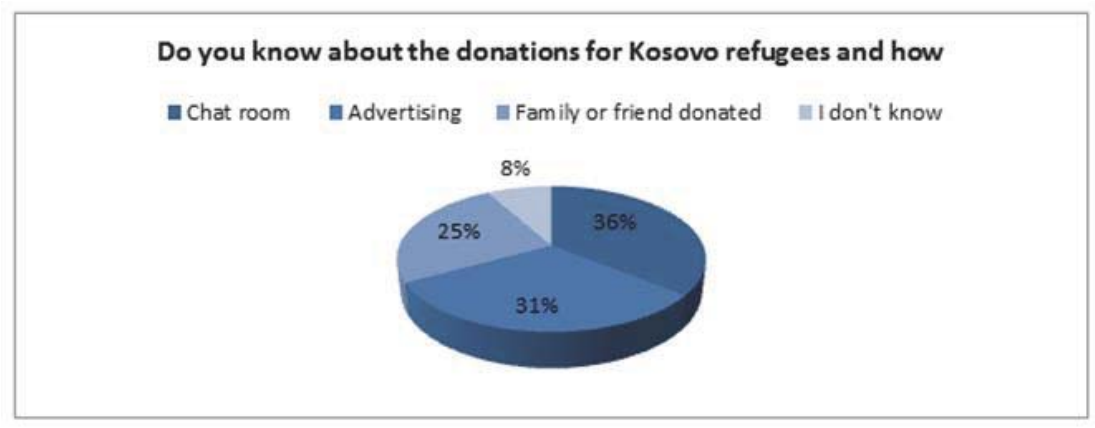

Another question was how did you got in contact with the specific chat rooms and communities discussing Kosovo's Crises and we have the following information: because of my friend with $35 \%$ followed by the because of my brother $33 \%$ and $28 \%$ sister, because of my parents answered $4 \%$ and less importance attaches because of my boyfriend/girlfriend $1 \%$.

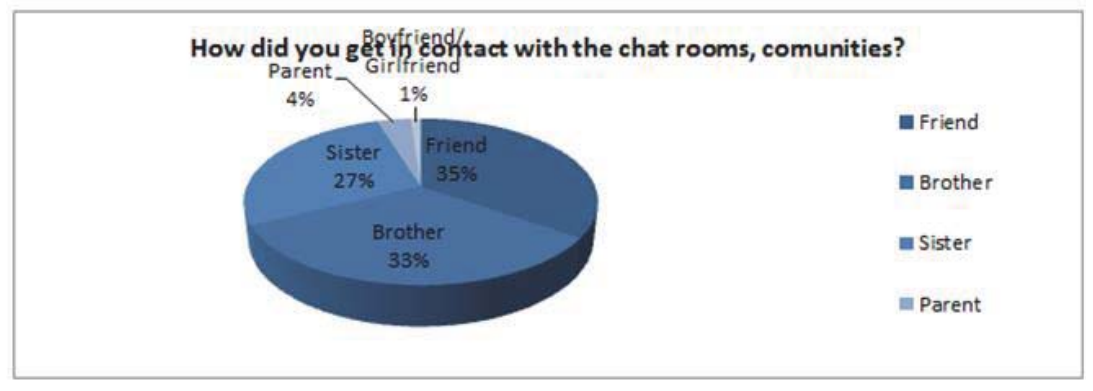

The Next question was how many hours a day they spent in these chat rooms discussing the main topics of the Kosovo War and its development: $39 \%$ of respondents state that spend at least 6 hours a day, 31\% said they had followed the discussing for 2- 3 hours, $21 \%$ of respondents claimed less than 1 hour, and $9 \%$ of the students claimed they didn't follow it at all. We believe that the actual data is more or less exact due to the fact that there had been evidence of the students spending the whole night in the above mentioned chat rooms ${ }^{9}$

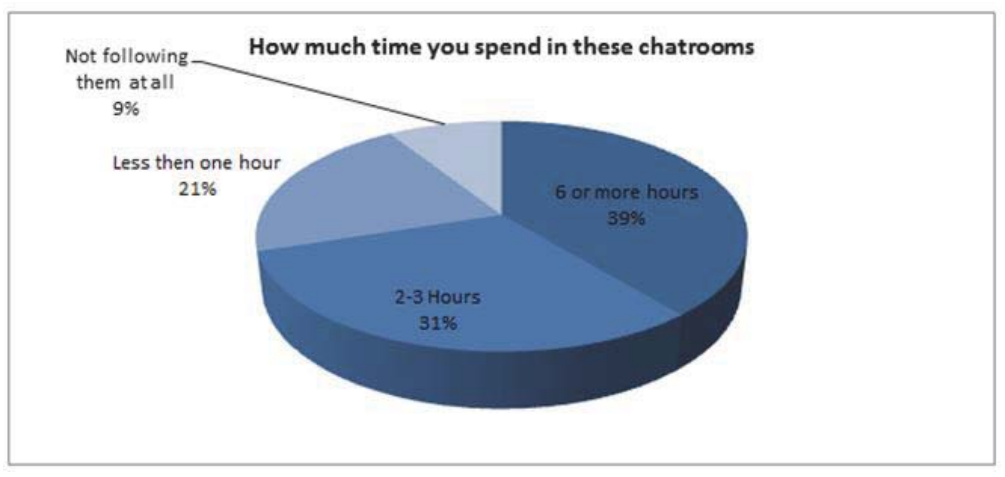

${ }^{8}$ Moody, M. (2010). Teaching Twitter and Beyond: Tip for Incorporating Social Media in Traditional Courses. Journal of Magazine \& New Media Research 11(2): pp. 1-9.

${ }^{9}$ E. Hargittai, 2007. "Whose space? Differences among users and non-users of social network sites," Journal of Computer-Mediated Communication, volume 13, number 1 , article 14 
To back up the above data below is a graph of the information taken from the Institutes of statistics of Albania and Machedoni, the institute of Media and the Gallup institution in highlighting the data how the information was distributed in the Balkans in 1997-2004 41\% of information comes thru chat rooms, blogs or comunities, while those follow the Public media are $38 \%$, regularly reading newspapers is $21 \%$ and the number those who use different of the above sources is $0 \%$. ${ }^{10}$ This shows that the main way of information back then were actually the chat rooms and communities even more then the electronical media ${ }^{11}$.

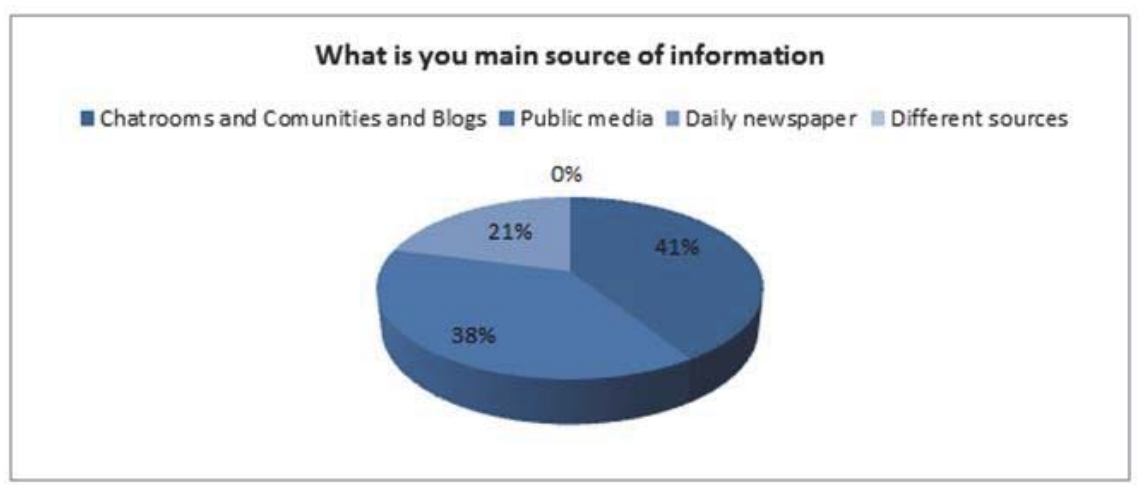

\section{Conclusions}

As already demonstrated the main sources of information at the time to the crises the Kosovo was going thru were the chat rooms and the communities. Actually there were around 17 thousand chat rooms and communities at the time mainly ad operated by Albanians which were serving as a different source of information regarding the crises and possible ways to help the refugees. It provided a much more extended network then the actual media coverage, and it was so much more important because people were sharing ideas and information and were trying to come to the aid of those that were in the middle of a conflict ${ }^{12}$. One of the most not touched themes of discussions is the way the social media like chats and communities were utilized to make a connection between the nationals living inside Albanian territory and those outside $\mathrm{it}^{13}$, and the way it served as a communication way to provide help, donations and reunification for a lot of families divided by the war. So all in all the main conclusions are as below:

a. The social media impacted in the humanitarian part of the war of Kosovo

b. It provided information and help for the refuges

c. It established a communication road for the divided families

d. It impacted the new generation in becoming more active in the crises of Kosovo.

All in all social media is a powerful mean and no matter when it started or how many crises it influenced it need more study and control means to generate it in a useful tool for society.

\section{References}

Gao, F. , Luo, T. , \& Zhang, K. (2012). Tweeting for learning: A critical analysis of research on microblogging in education published in 2008- 2011. British Journal of Educational Technology

INSTAT, Albanian In Numbers 2012-2013

E. Hargittai, 2007. "Whose space? Differences among users and non-users of social network sites," Journal of Computer-Mediated Communication, volume 13 , number 1 , article 14

INSTAT, Albanian In Numbers 1999-2004

Junco, R. , Heiberger, G. , \& Loken, E. (2011). The effect of Twitter on college student engagement and grades. Journal of Computer Assisted Learning,

Moody, M. (2010). Teaching Twitter and Beyond: Tip for Incorporating Social Media in Traditional Courses. Journal of Magazine \& New

10 INSTAT, Albanian In Numbers 1999-2004, pg 108

11 Junco, R., Heiberger, G., \& Loken, E. (2011). The effect of Twitter on college student engagement and grades. Journal of Computer Assisted Learning, 27(2), 119-132..

${ }_{12}$ Gao, F., Luo, T., \& Zhang, K. (2012). Tweeting for learning: A critical analysis of research on microblogging in education published in 2008- 2011. British Journal of Educational Technology, 43(5), 783-801.

${ }_{13}$ INSTAT, Albanian In Numbers 2012-2013, pg 78 
Media Research

Kist,W. (2012). Class get ready to tweet: Social media in the classroom. Our children.

J. Schroeder and T. J. Greenbowe, 2009. "The chemistry of Facebook: Using social networking to create an online community for the organic chemistry laboratory," Innovate, volume 5, number 4,

Moody, M. (2010). Teaching Twitter and Beyond: Tip for Incorporating Social Media in Traditional Courses. Journal of Magazine \& New Media Research

G. Salaway, J. Caruso, and R. Mark, 2008. The ECAR study of undergraduate students and information technology, 2008. Boulder, Colo. : EDUCAUSE Center for Applied Research, at http: //www. educause. edu/ecar, accessed 15 November 2011.

Webster Dictionary 2012,

Van Dijck, Jose The Culture of Connectivity: A Critical History of Social Media, January 30, 2013

http: //www. inquisitr. com/830664/the-history-of-social-media-when-did-it-really-begin-you-may-be-surprised-infographic/ 